\title{
Relationship of oxidative stress and endothelial dysfunction in sleep apnoea
}

\author{
B. Jurado-Gámez*, M.C. Fernandez-Marin*, J.L. Gómez-Chaparro\#,†, \\ L. Muñoz-Cabrera*, J. Lopez-Barea", F. Perez-Jimenez ${ }^{+}$and J. Lopez-Miranda ${ }^{+}$
}

ABSTRACT: The aim of the present study was to evaluate ischaemic reactive hyperaemia (IRH) in obstructive sleep apnoea (OSA) and its relationship with oxidative stress.

We studied 69 consecutive patients referred to our Sleep Unit (Reina Sofia University Hospital, Cordoba, Spain). Patients with chronic diseases or those taking medication were excluded. IRH was assessed before and after polysomnography. Morning IRH and oxidative stress markers were compared between patients with (apnoea-hypopnoea index $(\mathrm{AHI}) \geqslant 5$ ) and without $(\mathrm{AHI}<5)$ OSA. Measurements were repeated in 25 severe OSA patients after continuous positive airway pressure (CPAP) therapy.

We included 46 OSA patients (mean \pm SD AHI $49 \pm 32.1$ ) and 23 non-OSA subjects (AHI $3 \pm 0.9$ ). The OSA patients showed a significant worsening of morning IRH, and a significant increase in malondialdehyde and 8-hydroxydeoxyguanosine levels. Only the oxygen desaturation index independently explained morning IRH, while malondialdehyde levels showed a weak effect on IRH. In severe OSA patients, IRH improved significantly after CPAP treatment, as did malondialdehyde, 8-hydroxydeoxyguanosine and protein carbonyl levels.

In OSA patients, endothelial dysfunction and oxidative stress were observed, and IRH worsened after sleep. The increase in oxidative stress was not associated with IRH, while intermittent hypoxia was strongly associated with IRH. In severe OSA patients, CPAP treatment improved oxidative stress and endothelial function.

KEYWORDS: Atherosclerosis, continuous positive airway pressure, endothelial function, obstructive sleep apnoea, oxidative stress

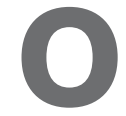
bstructive sleep apnoea (OSA) is characterised by snoring, witnessed apnoeas, unrefreshing sleep and excessive daytime sleepiness [1]. These symptoms are due to frequent episodes of upper airway collapse, resulting in arousals and sleep disruption. The respiratory events are accompanied by dips in arterial oxygen saturation measured by pulse oximetry $\left(\mathrm{S}_{\mathrm{p}}, \mathrm{O}_{2}\right)$. Hypoxia-reoxygenation episodes can occur repeatedly during the night, and have been associated with an increased risk for cardiovascular diseases, including systemic hypertension, coronary artery disease, cerebrovascular disease and cardiac arrhythmias [2-5]. Nevertheless, evaluating the involvement of OSA in cardiovascular disease is complex due to the high prevalence of smoking, high blood pressure and diabetes mellitus in OSA patients. Moreover, OSA may cause hypertension and insulin resistance.

Various mechanisms link OSA to an increase in vascular diseases [6-9].These mechanisms can produce endothelial dysfunction, an early indicator of vascular disease. This is of great epidemiological importance, as it can favour or accelerate the process of atherogenesis and the development of cardiovascular disease $[6,8,10,11]$.

Oxidative stress affects important macromolecules, especially lipid peroxidation [12], as well as producing DNA and protein damage [13]. To date, the impact of oxidative stress on these macromolecules in patients with OSA has only been partially studied and its role in endothelial dysfunction is not conclusive [14-16].

It has been proposed that nocturnal hypoxaemia may be the source of oxidative stress in OSA and that it is this mechanism that produces endothelial dysfunction. These changes can improve after continuous positive airway pressure (CPAP) treatment.

A prospective study was designed with the following objectives: 1) to evaluate whether endotheliumdependent ischaemic reactive hypaeremia (IRH) is altered in OSA patients compared with a control group; 2) to study the relationship between

\section{AFFILIATIONS}

*Sleep Unit, Dept of Respiratory Medicine, Reina Sofia University Hospital,

\#Dept of Biochemistry and Molecular Biology, University of Córdoba,

"Health District of Córdoba, Cordoba, and

+Lipid and Atherosclerosis Unit, IMIBIC/Reina Sofia University

Hospital/University of Cordoba, CIBER Fisiopatología Obesidad y Nutrición (CB06/03), Instituto de Salud Carlos III, Madrid, Spain.

CORRESPONDENCE

B. Jurado-Gámez

Servicio de Neumología

Unidad del Sueño

Hospital Universitario Reina Sofía

Avenida de Menéndez Pidal s/n

14004 Córdoba

Spain

E-mail: bjg01co@hotmail.com

Received:

Feb 192010

Accepted after revision:

June 272010

First published online:

July 222010

European Respiratory Journal Print ISSN 0903-1936 Online ISSN 1399-3003 
oxidative stress and IRH in these patients; and 3) to determine whether CPAP in OSA patients improves endothelial function and oxidative stress.

\section{PATIENTS AND METHODS \\ Setting}

The study was carried out in the Sleep Unit of the Reina Sofía University Hospital, Cordoba, Spain.

\section{Subjects}

The sample was recruited from consecutive patients who were referred to the Sleep Unit between October 2007 and June 2008, and underwent polysomnographic studies due to the following symptoms: snoring, unrefreshing sleep and excessive daytime sleepiness (Epworth scale score >11) [17]. Patients were eligible for the study if they were 35-65 yrs of age and agreed to participate. Patients were excluded from the study if they had $\mathrm{Sp}, \mathrm{O}_{2}<94 \%$ (breathing room air), congestive cardiac failure, hepatic cirrhosis, chronic renal insufficiency, Global Initiative for Chronic Obstructive Lung Disease stage III-IV chronic obstructive pulmonary disease, thyroid dysfunction, rheumatoid arthritis, or any other chronic or severe inflammatory diseases. Smokers, patients with drug addictions, and hypertensive patients treated with calcium antagonists, nitrates, $\alpha$ - or $\beta$-blockers, or angiotensin-converting enzyme inhibitors were also excluded. After polysomnography, subjects were classified as either OSA patients $(n=46$; apnoeahypopnoea index $(\mathrm{AHI}) \geqslant 5$ ) or non-OSA subjects (control group, $\mathrm{n}=23$; $\mathrm{AHI}<5)$.

\section{Study design}

This was a prospective study, with consecutive sampling of those subjects evaluated in our Sleep Unit who met the inclusion criteria. All patients underwent a complete physical examination and their medical histories were taken, paying special attention to symptoms and signs suggesting respiratory sleep disorders. They were asked about tobacco usage and medication consumption. Their body mass index (BMI) was calculated using the formula: weight in kilograms $\times$ (height in metres) $)^{2}$.

After $\geqslant 15 \min$ rest, $\mathrm{Sp}_{\mathrm{O}} \mathrm{O}_{2}$ was measured with a Pulsox 300i pulse oximeter (Konica Minolta Sensing, Shanghai, China) while the subject was awake and breathing room air. Sleep was studied using overnight polysomnography, and endothelial function was determined before polysomnography (night-time measurement) and afterwards (morning measurement). After evaluating nocturnal endothelial function, blood pressure was taken with the patient lying face up and resting for $\geqslant 5 \mathrm{~min}$ (HG Erkameter 300, Erka, Bad Tolz, Germany).

Patients with moderate or severe OSA received CPAP treatment [18]. Pressure was titrated using an auto-CPAP device (GoodKnight 420 E auto-CPAP, Nellcor Puritan Bennett, Boulder, CO, USA) following American Sleep Disorders Association (ASDA) guidelines [19]. After 3 months of treatment $\left(\mathrm{CPAP}>5 \mathrm{~h} \cdot\right.$ night $^{-1}$ ), all tests were repeated under identical conditions. In this phase, we excluded those patients who presented significant weight changes $(>3 \%$ gain or loss), were being treated with new medications or who presented a new pathology.
Informed consent was obtained from all subjects. The study was approved by the ethics committee of the Reina Sofía University Hospital.

\section{Methods}

Polysomnography

A polysomnograph was used (SomnoScreen ${ }^{\mathrm{TM}}$; SomnoMedics, Randersacker. Germany). The test began at 00:00 h and concluded at 07:30 h. We registered two electroencephalogram channels (C4/A1 and C3/A2), electro-oculogram, submental and tibial electromyogram, and airflow by pressure signal. Snoring, thoracic and abdominal effort, electrocardiographic derivation (V2), and $\mathrm{Sp}_{\mathrm{p}} \mathrm{O}_{2}$ were also monitored. Recordings were staged according to the system of Rechtschaffen and Kales. Apnoea was defined as a significant decrease (>90\%) in oronasal flow of $\geqslant 10 \mathrm{~s}$, and hypopnoea as an evident decrease in airflow $>30 \%$, but $<90 \%$, and associated with either oxygen desaturation of $\geqslant 3 \%$ and/or arousal. The following respiratory variables were monitored: $\mathrm{AHI}$, defined as the sum of apnoeas and hypopnoeas per hour of sleep; minimum $S_{\mathrm{p}}, \mathrm{O}_{2}$ reached during sleep; the oxygen desaturation index, defined as the number of decreases in $\mathrm{Sp}, \mathrm{O}_{2} \geqslant 3 \%$ per hour of sleep; and, finally, the sleep time spent with $\mathrm{Sp}_{\mathrm{p}, \mathrm{O}_{2}}<90 \%$ was estimated. All studies were reviewed and interpreted by a study-blinded, board-certified sleep medicine physician. Polysomnograms were considered valid for diagnosis when $\geqslant 180 \mathrm{~min}$ sleep were recorded.

\section{Endothelial function}

A laser-Doppler linear Periflux 5000 (Perimed SA, Stockholm, Sweden) was used to measure IRH. The methodology has been described previously [20]. Briefly, with the patient lying in the supine position in a room with a stable temperature $\left(20-22^{\circ} \mathrm{C}\right)$, the blood pressure cuff was placed $5 \mathrm{~cm}$ above the elbow, while the laser probe was attached to the palmar surface of the second finger of the same dominant hand. After a 5-min resting period, basal capillary flow was measured for $1 \mathrm{~min}$ $\left(t_{0}\right)$. Thereafter, $4 \mathrm{~min}$ distal ischaemia was induced by inflating the cuff to suprasystolic pressure $(200-220 \mathrm{mmHg})$. The cuff was then deflated and, after $30 \mathrm{~s}$, the flow was recorded for $1 \mathrm{~min}\left(t_{\mathrm{d}}\right)$. The data obtained were recorded and stored using PeriSoft Software for Windows (Perimed SA). The values of the area under the curve (AUC) of the $t_{0}$ and $t_{\mathrm{d}}$ timepoints were analysed. These data were used to calculate the increase in post-ischaemic flow by means of the formula: $\mathrm{IRH}=\left(\mathrm{AUC} t_{\mathrm{d}}-\mathrm{AUC} t_{0}\right) \times 100 \mathrm{AUC} t_{0}$. The first IRH registration took place at 23:00 $\mathrm{h}$ and the second at 07:30 h, after the polysomnography and blood extraction. This method has an interstudy variability of $8.85 \%$ and intrastudy variability of $8.7 \%$ [20].

\section{Oxidative stress biomarker determination}

Blood samples were obtained at 07:00 h, after one night of fasting. Whole blood was collected in Vacutainer tubes (BD Diagnostic Systems, Franklin Lakes, NJ, USA) following our standard hospital extraction protocol. Blood was allowed to cool and coagulate for $30 \mathrm{~min}$, and was then centrifuged at $1500 \times g$ and $4{ }^{\circ} \mathrm{C}$ for $10 \mathrm{~min}$. The resulting plasma was aliquoted and frozen at $-80^{\circ} \mathrm{C}$ for subsequent analysis. The entire process was carried out in $\leqslant 60 \mathrm{~min}$ after extraction. Total plasma proteins were measured with Coomassie Brilliant 
Blue G-250 (Bio-Rad, Richmond, CA, USA), using the Bradford method.

Protein carbonyl levels were determined in plasma using an ELISA (BioCell PC, Papatoetoe, New Zealand), measuring absorbence at $620 \mathrm{~nm}$, according to the manufacturer's instructions. The concentration of protein carbonyls (in nanomoles per milligram of protein) was established using a calibration curve with known concentration patterns. The standard curve was linear in the range of $0-3.36 \mathrm{nmol} \cdot \mathrm{mg}$ protein $^{-1}$. The intra-assay variation of samples was $\sim 5 \%$, based on the material provided with the kit.

DNA oxidative damage was measured using an ELISA (Bioxytech 8-OHdG-EIA Kit; Oxis International, Beverly Hills, CA, USA) on $8 \times 12$ microtitre plates, according to the manufacturer's specifications. The concentration of 8-hydroxydeoxyguanosine (in nanograms per millilitre) was calculated with a calibration line obtained from known 8-hydroxydeoxyguanosine concentrations. The standards range was $0.5-$ $200.0 \mathrm{ng} \cdot \mathrm{mL}^{-1}$. The intra-assay variation of samples was $2.7 \%$.

Plasma malondialdehyde values, which measure lipid peroxidation, were determined at $586 \mathrm{~nm}$ in triplicate for each subject using the Bioxytech LPO 586 test (Oxis International), according to with the manufacturer's specifications. Malondialdehyde concentration (micromolar) was calculated from a calibration line with known malondialdehyde levels. The measurements were performed in microtitre plates using a DTX 880 Multimode Detector (Beckman-Coulter, Fullerton, CA, USA). The unused wells at the edges of the plates were filled with water to maintain a homogenous temperature throughout the plate. The standard curve was linear over the range $0.5-4.0 \mu \mathrm{M}$ and the lower limit of detection was defined as $5,185 \mathrm{SD}$ from the blank absorbance. The total variation coefficient was $2 \%$.

\section{Variables and statistical analysis}

Data are presented as median (interquartile range) for continuous variables, and $\mathrm{n}(\%)$ for categorical variables. Continuous variables before and after polysomnography were compared using the Mann-Whitney U-test. Confidence intervals for the differences between two means were determined at a level of 95\%. Spearman's rank test was used for correlation analysis. A p-value $<0.05$ was considered to be statistically significant.

To analyse the relationship between the dependent variable (IRH) and predictive variables, a multivariate analysis was carried out using a multiple linear regression model. In the analysis, endothelial function was taken as the dependent variable, determined by analysis of the AUC $t_{0}$ and $A U C t_{\mathrm{d}}$. Independent variables were nocturnal $\mathrm{Sp}_{\mathrm{p}} \mathrm{O}_{2}$ values (oxygen desaturation index, sleep time spent with $\mathrm{Sp}_{\mathrm{p}} \mathrm{O}_{2}<90 \%$ and mean $\mathrm{Sp}, \mathrm{O}_{2}$ ) and oxidative stress biomarkers (malondialdehyde, 8-hydroxydeoxyguanosine and protein carbonyls). The differences between values before and after CPAP treatment were compared using the Wilcoxon test.

Data were analysed using the Statistical Package for Social Sciences (SPSS) for Windows 14.0 (SPSS Inc., Chicago, IL, USA).

\section{RESULTS}

\section{Basal parameters}

76 subjects were pre-selected, of whom seven were excluded. The reasons for exclusion were the following: two patients were smokers, two were taking $\beta$-blockers and calcium antagonists, and three had $\mathrm{Sp}_{\mathrm{O}} \mathrm{O}_{2}<94 \%$ while awake on the night of the polysomnographic study. The remaining 69 subjects were included in the study. After polysomnography, the subjects were classified as either OSA patients $(n=46$; apnoea-hypopnoea index $(\mathrm{AHI}) \geqslant 5$ ) or non-OSA subjects (control group, $n=23$; AHI $<5$ ). Figure 1 shows the study sequence and the composition of the different groups.

Table 1 summarises the baseline characteristics of the patients included in this study. There were no significant differences between the two groups regarding age, sex or BMI. No differences were observed either in waking $\mathrm{Sp}, \mathrm{O}_{2}$ or in biochemical parameters, except for triglyceride values that were significantly elevated in the OSA patients.

\section{Endothelial function and oxidative stress}

Table 2 shows that there were no significant differences in nocturnal IRH between the two groups studied before sleep onset $(p=0.904)$. However, compared with the control group, OSA patients showed a significant decrease in morning IRH $(p<0.001)$. In these patients, differences were observed in all variables related to the disease (AHI) and nocturnal $\mathrm{Sp}_{\mathrm{p}} \mathrm{O}_{2}$ (oxygen desaturation index, sleep time spent with $\mathrm{Sp}, \mathrm{O}_{2}<90 \%$, minimum $\mathrm{Sp}_{\mathrm{p}} \mathrm{O}_{2}$ and mean $\mathrm{Sp}, \mathrm{O}_{2}$ ). With regards to oxidative stress, plasma levels of malondialdehyde and 8-hydroxydeoxyguanosine were significantly higher in OSA patients than in the control group.

The correlations of IRH with various sociodemographic, respiratory and oxidative stress variables in OSA patients are shown in table 3, where a correlation between nocturnal $S \mathrm{p}, \mathrm{O}_{2}$, malondialdehyde, 8-hydroxydeoxyguanosine and IRH values can be observed. To examine independent predictors of IRH in

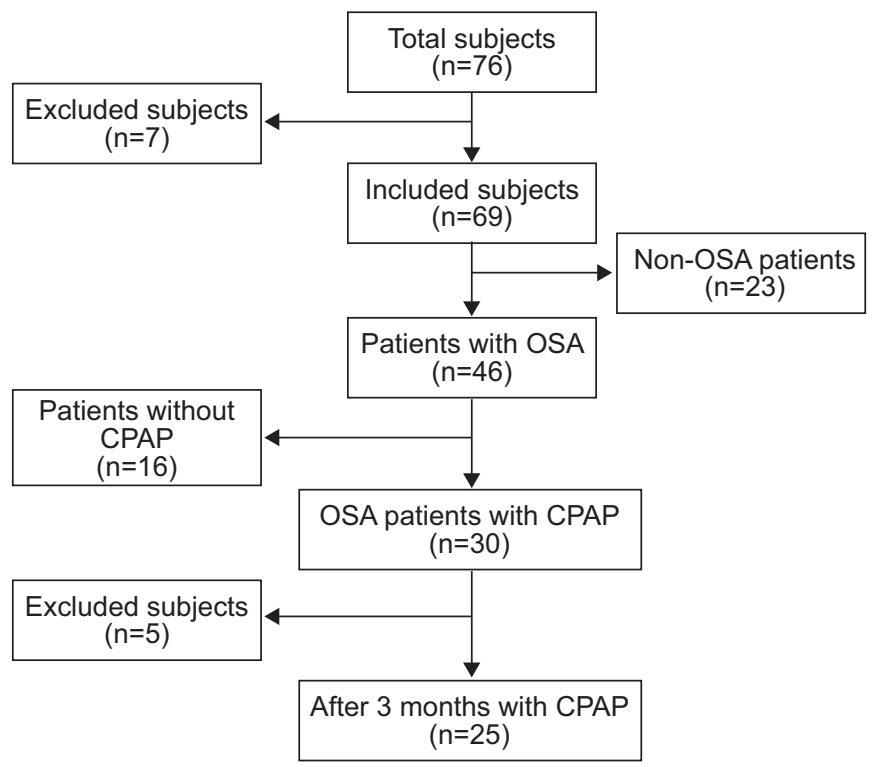

FIGURE 1. Flow chart showing study cohort and different subgroups. OSA obstructive sleep apnoea; CPAP: continuous positive airway pressure. 


\begin{tabular}{|c|c|c|c|}
\hline $\begin{array}{l}\text { Characte } \\
\text { apnoea ( }\end{array}$ & $\begin{array}{l}\text { ics of patien } \\
\text { A) and cont }\end{array}$ & $\begin{array}{l}\text { s with obstructive } \\
\text { ols }\end{array}$ & sleep \\
\hline Variable & OSA patients & Non-OSA patients & p-value \\
\hline Subjects $\mathrm{n}$ & 46 & 23 & \\
\hline Age yrs & $47(40-47)$ & $48(44-51)$ & 0.738 \\
\hline Males & $34(73)$ & $15(61)$ & $0.575^{\#}$ \\
\hline BMI $\mathbf{k g} \cdot \mathrm{m}^{-2}$ & $31(27-34)$ & $30(28-31)$ & 0.061 \\
\hline Waking $\mathrm{Sp}, \mathrm{O}_{2} \%$ & 95 (95-96) & 95 (94-96) & 0.438 \\
\hline Ex-smokers & $14(30)$ & $5(22)$ & $0.572^{\#}$ \\
\hline Diabetes mellitus & $2(4)$ & $2(8)$ & $0.596^{\#}$ \\
\hline Fasting glucose $\mathrm{mg} \cdot \mathrm{dL}^{-1}$ & 91 (88-98) & $91(85-108)$ & 0.728 \\
\hline $\begin{array}{l}\text { Creatinine clearance } \\
\mathrm{mL} \cdot \mathrm{min}^{-1}\end{array}$ & $105(102-111)$ & $109(102-115)$ & 0.642 \\
\hline Total cholesterol $\mathrm{mg} \cdot \mathrm{dL}^{-1}$ & $182(164-205)$ & $181(165-200)$ & 0.478 \\
\hline $\mathrm{HDL}$ cholesterol $\mathrm{mg} \cdot \mathrm{dL}^{-1}$ & $48(38-52)$ & $46(38-63)$ & 0.631 \\
\hline Triglycerides $\mathrm{mg} \cdot \mathrm{dL}^{-1}$ & $109(77-147)$ & 79 (67-99) & 0.044 \\
\hline
\end{tabular}

Data are presented as median (interquartile range) or $\mathrm{n}(\%)$, unless otherwise stated. p-values represent estimated difference in median $(95 \% \mathrm{Cl})$ on MannWhitney testing, unless otherwise stated. BMI: body mass index; $\mathrm{Sp}, \mathrm{O}_{2}$ : arterial oxygen saturation measured by pulse oximetry; HDL: high-density lipoprotein. \#: Chi-squared test.

patients with OSA, a stepwise multiple linear regression was performed. The oxygen desaturation index was the only significant independent predictor of IRH (adjusted $\mathrm{r}^{2}=0.181$, $\mathrm{F}=2.986, \beta=-0.557 ; \mathrm{p}=0.011$ ).

As explained previously, significant correlations were observed between IRH, and both malondialdehyde and 8hydroxydeoxyguanosine, although the multiple lineal regression showed only a tendency to explain the IRH results (adjusted $\mathrm{r}^{2}=0.195, \mathrm{~F}=2.419, \beta=-0.234 ; \mathrm{p}=0.082$ ).
Of the 46 patients with OSA, CPAP treatment was prescribed for 30 patients according to ASDA criteria [19]. Of these, one patient refused treatment and four were excluded for noncompliance with $\geqslant 4 \mathrm{~h} \cdot$ day $^{-1}$ CPAP therapy. After 3 months of CPAP treatment, these patients underwent the same tests again under the same conditions, including polysomnography, IRH measurement and blood analysis for the oxidative stress study. In the 25 patients who completed CPAP treatment (table 4), no significant changes were observed in BMI. After $\geqslant 3$ months of treatment, CPAP corrected respiratory events (AHI), alterations in nocturnal $\mathrm{Sp}, \mathrm{O}_{2}$ (minimum and mean $\mathrm{Sp}_{\mathrm{p}} \mathrm{O}_{2}$, oxygen desaturation index and sleep time spent with $\mathrm{Sp}, \mathrm{O}_{2}<90 \%$ ) and decreased blood pressure significantly (table 4). Moreover, an improvement in oxidative stress was observed, with significantly lower malondialdehyde $(p=0.001), 8$-hydroxydeoxyguanosine $(p=0.001)$ and protein carbonyl $(p=0.021)$ levels. When comparing values before and after CPAP treatment, it was seen that the differences in IRH values were correlated with AHI, oxygen desaturation index, and malondialdehyde and 8-hydroxydeoxyguanosine levels (fig. 2), while there were no significant correlations with sleep time spent with $S_{p}, \mathrm{O}_{2}<90 \%(\rho=-0.205$; $p=0.325)$ or protein carbonyl levels $(\rho=-0.194 ; p=0.353)$.

\section{DISCUSSION}

To our knowledge, this study is the first in which patients with OSA were assessed for the impact of oxidative stress on lipids, DNA and proteins, as well as its association with endothelial function. This study shows that, in comparison with a control group, OSA patients suffer from greater endothelial dysfunction. AHI and the variables evaluating nocturnal $S \mathrm{p}, \mathrm{O}_{2}$ were correlated with IRH, although the number of decreases in $\mathrm{Sp}, \mathrm{O}_{2}$ (oxygen desaturation index) was the only parameter that was independently associated with endothelial dysfunction. Malondialdehyde and 8-hydroxydeoxyguanosine levels were

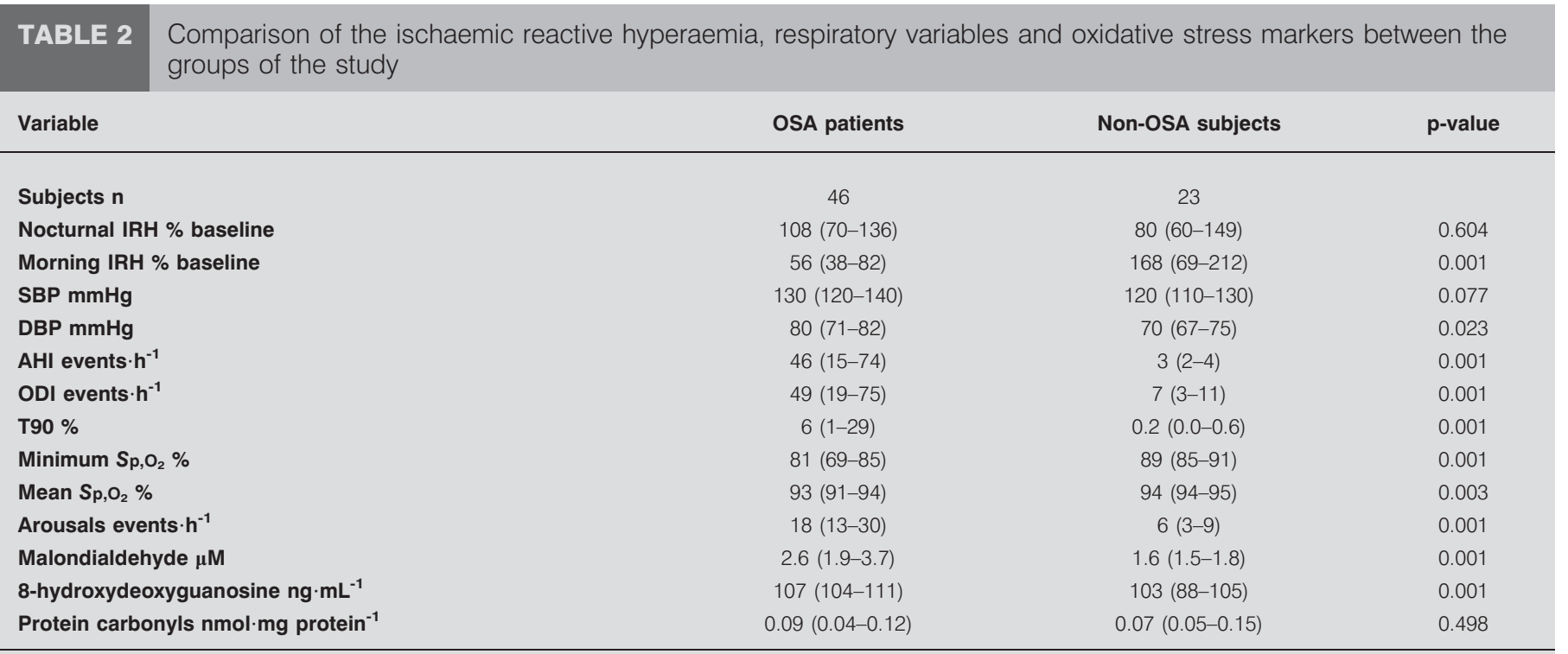

Data are presented as meadian (interquartile range), unless otherwise stated. OSA: obstructive sleep apnoea; IRH: ischaemic reactive hyperaemia; SBP: systolic blood pressure; DBP: diastolic blood pressure; AHI: apnoea-hypopnoea index; ODI: oxygen desaturation index; T90: sleep time spent with arterial oxygen saturation measured by pulse oximetry $\left(\mathrm{Sp}, \mathrm{O}_{2}\right)<90 \%$. 


\begin{tabular}{|c|c|c|c|}
\hline \multirow{2}{*}{$\begin{array}{l}\text { TABLE } 3 \\
\text { Variable }\end{array}$} & \multicolumn{3}{|c|}{$\begin{array}{l}\text { Correlations between clinical variables, } \\
\text { respiratory events oxidative stress markers and } \\
\text { ischaemic reactive hyperaemia }(\mathrm{IRH})\end{array}$} \\
\hline & & IRH $\rho$-value & p-value \\
\hline \multicolumn{2}{|l|}{ Age yrs } & -0.068 & 0.579 \\
\hline \multicolumn{2}{|l|}{$B M I \mathbf{k g} \cdot \mathrm{m}^{-2}$} & -0.076 & 0.537 \\
\hline \multicolumn{2}{|l|}{ Sex } & 0.053 & 0.913 \\
\hline \multicolumn{2}{|c|}{ AHI events $\cdot h^{-1}$} & 0.542 & 0.001 \\
\hline \multicolumn{2}{|c|}{ ODI events $\cdot h^{-1}$} & -0.565 & 0.001 \\
\hline \multicolumn{2}{|c|}{ T90 \% } & -0.480 & 0.001 \\
\hline \multicolumn{2}{|c|}{ Minimum $\mathrm{Sp}, \mathrm{O}_{2} \%$} & 0.311 & 0.051 \\
\hline \multicolumn{2}{|c|}{ Mean $\mathrm{Sp}, \mathrm{O}_{2} \%$} & 0.426 & 0.002 \\
\hline \multicolumn{2}{|c|}{ Waking $\mathrm{Sp}_{\mathrm{p}} \mathrm{O}_{2} \%$} & 0.193 & 0.126 \\
\hline \multicolumn{2}{|c|}{ Arousals events $\cdot \mathrm{h}^{-1}$} & -0.189 & 0.209 \\
\hline \multicolumn{2}{|c|}{ Total cholesterol $\mathrm{mg} \cdot \mathrm{dL}^{-1}$} & 0.088 & 0.689 \\
\hline \multicolumn{2}{|c|}{$\mathrm{HDL}$ cholesterol $\mathrm{mg} \cdot \mathrm{dL}^{-1}$} & -0.203 & 0.352 \\
\hline \multicolumn{2}{|c|}{ Triglycerides $\mathrm{mg} \cdot \mathrm{dL}^{-1}$} & 0.209 & 0.315 \\
\hline \multicolumn{2}{|c|}{ Malondialdehyde $\mu \mathrm{M}$} & -0.371 & 0.002 \\
\hline \multicolumn{2}{|c|}{ 8-hydroxydeoxyguanosine $\mathrm{ng} \cdot \mathrm{mL}^{-1}$} & -0.271 & 0.025 \\
\hline \multicolumn{2}{|c|}{ Protein carbonyls $\mathrm{nmol} \cdot \mathrm{mg}$ protein $^{-1}$} & 0.163 & 0.180 \\
\hline \multicolumn{2}{|l|}{ SBP mmHg } & -0.117 & 0.355 \\
\hline \multicolumn{2}{|l|}{ DBP mmHg } & -0.243 & 0.051 \\
\hline \multicolumn{4}{|c|}{$\begin{array}{l}\text { BMI: body mass index; } \mathrm{AHI} \text { : apnoea-hypopnoea index; ODI: oxygen } \\
\text { desaturation index; T90: sleep time spent with arterial oxygen saturation } \\
\text { measured by pulse oximetry }\left(\mathrm{Sp}, \mathrm{O}_{2}\right)<90 \% \text {; } \mathrm{HDL} \text { : high-density lipoprotein; } \mathrm{SBP} \text { : } \\
\text { systolic blood pressure; } \mathrm{BBP} \text { : diastolic blood pressure. }\end{array}$} \\
\hline
\end{tabular}

significantly elevated in patients with OSA, although these variables were not independent predictors of IRH. Furthermore, after 3 months of CPAP treatment, the patients showed significant improvements in oxidative stress markers and endothelial function.

Endothelial dysfunction favours atherosclerosis and is considered to be a cardiovascular risk factor [8, 10]. Our study provides interesting data and, to the best of our knowledge, it is the first to compare nocturnal and morning IRH in the same patients, in order to accurately evaluate the effects of respiratory events on endothelial function. Both groups (patients with OSA and subjects without OSA) had similar values for nocturnal IRH (table 2). However, significant worsening of morning IRH was observed in OSA patients.

In our study, malondialdehyde and 8-hydroxydeoxyguanosine levels differed in the OSA and control groups, confirming that oxidative stress is greater in OSA patients. However, an association of oxidative stress with endothelial function was not observed. There have been several studies with a limited sample sizes that have studied oxidative stress and endothelial dysfunction. They compared the impact of CPAP [14], allopurinol [15] or vitamin C [16]. They reported, as did our study, correlations between some oxidative stress markers and endothelial dysfunction. Nevertheless, these markers were not predictors of IRH. The studies mentioned above did not study causality and carried out therapeutic interventions to evaluate oxidative stress [14-16]. Furthermore, some of the markers used were different and may not have the same biological role

\begin{tabular}{|c|c|c|c|c|}
\hline TABLE 4 & \multicolumn{4}{|c|}{$\begin{array}{l}\text { Respiratory variables, oxidative stress markers } \\
\text { and ischaemic reactive hyperaemia }(\mathrm{IRH}) \text { in } 25 \\
\text { patients with severe obstructive sleep apnoea } \\
\text { treated with continuous positive airway pressure } \\
\text { (CPAP) for } 3 \text { months. }\end{array}$} \\
\hline Variable & & Before CPAP & After CPAP & p-value \\
\hline \multicolumn{2}{|c|}{ BMI $\mathbf{k g} \cdot \mathrm{m}^{-2}$} & $33(30-36)$ & 32 (30-35) & 0.091 \\
\hline \multicolumn{2}{|c|}{$A H I$ events $\cdot h^{-1}$} & $71(52-85)$ & $2(1-3)$ & 0.001 \\
\hline \multicolumn{2}{|c|}{ ODI events $\cdot h^{-1}$} & $68(54-83)$ & $5(2-9)$ & 0.001 \\
\hline \multicolumn{2}{|c|}{$\mathrm{SapO}_{2}$ minimum, \% } & $72(62-82)$ & $91(86-92)$ & 0.001 \\
\hline \multicolumn{2}{|c|}{$\mathrm{SapO}_{2}$ mean,\% } & 92 (87-93) & 95 (93-96) & 0.035 \\
\hline \multicolumn{2}{|c|}{ T90 \% } & $22(5-40)$ & $0.4(0-1.4)$ & 0.001 \\
\hline \multicolumn{2}{|c|}{ Malondialdehyde $\mu \mathrm{M}$} & $3.2(2.5-4.2)$ & $1.9(1.6-2.2)$ & 0.001 \\
\hline \multicolumn{2}{|c|}{$\begin{array}{l}\text { 8-hydroxydeoxyguanosine } \\
\mathrm{ng} \cdot \mathrm{mL}^{-1}\end{array}$} & $107(105-114)$ & $102(101-106)$ & 0.001 \\
\hline \multicolumn{2}{|c|}{$\begin{array}{l}\text { Protein carbonyls } \mathrm{nmol} \cdot \mathrm{mg} \\
\text { protein }^{-1}\end{array}$} & $0.10(0.05-0.14)$ & $0.10(0.04-0.12)$ & 0.021 \\
\hline \multicolumn{2}{|c|}{ SBP mmHg } & $140(120-142)$ & $120(118-130$ & 0.001 \\
\hline \multicolumn{2}{|l|}{ DBP mmHg } & $80(77-90)$ & $70(68-80)$ & 0.001 \\
\hline \multicolumn{2}{|c|}{ Morning IRH \% baseline } & $47(33-74)$ & $127(89-148)$ & 0.001 \\
\hline
\end{tabular}

Data are presented as median (interquartile range), unless otherwise stated. BMI: body mass index; AHI: apnoea-hypopnoea index; ODI: oxygen desaturation index; $\mathrm{Sp}, \mathrm{O}_{2}$ : arterial oxygen saturation measured by pulse oximetry; T90: sleep time spent with $\mathrm{Sp}, \mathrm{O}_{2}<90 \%$; SBP: systolic blood pressure; DBP: diastolic blood pressure.

as those used in our study [14]. The markers used in our study have been shown to be valid in human pathology [13]

The relationship between endothelial function and respiratory parameters is controversial. NIETO et al. [21] observed a significant association between sleep time spent with $\mathrm{Sp}, \mathrm{O}_{2}$ $<90 \%$, and both baseline arterial diameter and the percentage of flow-mediated dilation. In contrast, KATO et al. [22] did not observe significant endothelial function differences between patients with OSA and a control group. In our study, IRH was not associated with the severity of hypoxaemia, as determined by sleep time spent with $\mathrm{Sp}_{\mathrm{O}} \mathrm{O}_{2}<90 \%$, but with intermittent hypoxia, as evaluated by the oxygen desaturation index. In a recent article, OSA patients with greater nocturnal desaturation had poorer endothelial function [23].

It is known that oxygen partial pressure regulates the expression of nitric oxide synthase. The systemic production of nitric oxide also worsens in OSA and the administration of oxygen significantly increases it [24].

Thus, a close relationship of both oxidative stress and endothelial dysfunction with nocturnal hypoxaemia is possible. Intermittent hypoxia was independently associated with a worsening of IRH in our study. These results are consistent with those reported by other authors [14-16]. Overall, our study suggests that there are probably other biological mechanisms related to intermittent hypoxaemia, besides oxidative stress, that can affect endothelial function. The release of inflammatory molecules and endothelial apoptosis, among others, has been described [5-8, 11, 25-27]. 

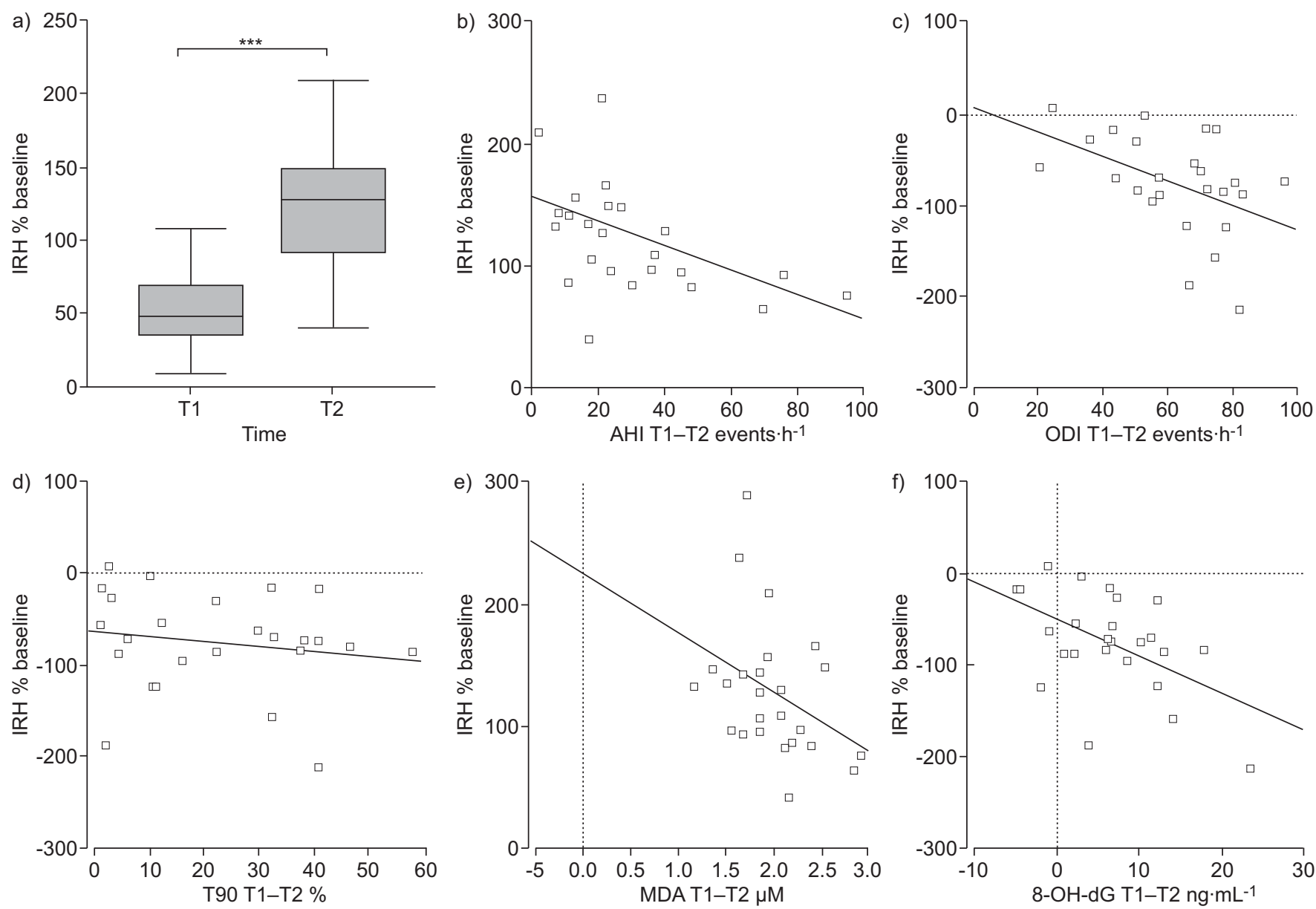

FIGURE 2. a) Differences in ischaemic reactive hyperaemia (IRH) values before (T1) and after (T2) continuous positive airway pressure treatment. Correlations of IRH with b) apnoea-hypopnoea index $(\mathrm{AH} ; \mathrm{r}=-0.412 ; \mathrm{p}=0.041)$, c) number of decreases in arterial oxygen saturation measured by pulse oximetry $\left(\mathrm{Sp}, \mathrm{O}_{2}\right) \geqslant 3 \%$ per hour of sleep $(\mathrm{ODI} ; \mathrm{r}=-0.482 ; \mathrm{p}=0.015)$, d) sleep time spent with $\mathrm{Sp}, \mathrm{O}_{2}<90 \%(\mathrm{~T} 90 ; r=-0.205 ; \mathrm{p}=0.325)$, e) malondialdehyde $(\mathrm{MDA} ; r=-0.407 ; p=0.044)$ and $\left.f\right)$ 8hydroxydeoxyguanosine $(8-\mathrm{OH}-\mathrm{dG} ; \mathrm{r}=-0.395 ; \mathrm{p}=0.050)$. ${ }^{* \star *}: \mathrm{p}<0.001$.

It can, therefore, be predicted that correcting intermittent hypoxia with CPAP can have an important influence on these parameters. In previous studies, improvement in endothelial dysfunction was observed in response to CPAP treatment [11, $23,24,28,29]$. It is also postulated that CPAP can alleviate oxidative stress $[11,30]$. CARPAGNANO et al. [31] showed that an increase in 8-isoprostane in exhaled breath condensate, which decreased significantly after CPAP treatment. Our study shows that, compared to the situation prior to treatment in severe OSA patients, IRH and oxidative stress improved significantly after CPAP treatment. This finding is not surprising, as CPAP treatment effectively corrects $\mathrm{AHI}$ and the effect of these events on nocturnal $\mathrm{Sp}_{\mathrm{p}} \mathrm{O}_{2}$. It was interesting to see that protein oxidation also improved with CPAP. To our knowledge, only one study has assessed the effect of oxidative stress on serum proteins, although it was carried out in patients on haemodialysis, a treatment which itself produces oxidative stress [32]. It is important to emphasise that protein carbonylation indicates more severe oxidative stress. This may explain the trend toward higher levels observed in OSA patients and that the most severe cases, when treated with CPAP, showed a global decrease in oxidative stress, including protein oxidation.

\section{Potential limitations of the study}

Our study was designed to compare the results obtained in OSA patients with those of a control group. However, the effect of the treatment was not controlled with a placebo, given the cardiovascular risk inherent in leaving severe OSA patients untreated [2-5]. In our patients with severe OSA (median AHI 71 events $\left.\cdot h^{-1}\right)$, it did not seem ethical to use suboptimal pressure (sham CPAP) for a period of $\leqslant 3$ months. In the study design, we controlled for factors not related to OSA that could also be associated with endothelial dysfunction; therefore, patients with severe diseases, including hypertension, and those under treatment with drugs that affect endothelial function were excluded. Obesity has been associated with endothelial dysfunction. Nevertheless, there was no change in $\mathrm{BMI}$ in those patients treated with CPAP, although significant improvements were observed in oxidative stress and IRH in this group. In our study, small, statistically significant differences were observed in oxidative stress markers. These were elevated in patients with OSA and the values decreased after CPAP treatment. The clinical relevance of these changes is unclear, although our study has shown that they are significantly relevant in themselves to produce changes in IRH. 
Therefore, in conditions of clinical practice and using an ample number of subjects, our study demonstrated that oxidative stress is not a factor that explains the IRH variability independently, reinforcing the idea that other mechanisms are involved, factors associated with intermittent hypoxaemia that can cause endothelial dysfunction. In fact, our study demonstrates a close relationship between intermittent hypoxia and deterioration of endothelial function, showing a significant improvement in the severe patients who were treated with CPAP. This finding is of great clinical importance, as treating OSA could have an impact on a preclinical vascular risk factor, possibly preventing the vascular complications subsequently associated with it.

\section{SUPPORT STATEMENT}

This work was supported by the Neumosur Foundation.

\section{STATEMENT OF INTEREST}

None declared.

\section{REFERENCES}

1 Young T, Peppard PE, Gottlieb DJ. Epidemiology of obstructive sleep apnea: a population health perspective. Am J Respir Med 2002; 165: 1217-1239.

2 Peker Y, Carlson J, Hedner J. Increased incidence of coronary artery disease in sleep apnoea: a long-term follow-up. Eur Respir J 2006; 28: 596-602.

3 Marín JM, Carrizo SJ, Vicente F, et al. Long-term cardiovascular outcomes in men with obstructive sleep apnoea-hypopnoea with or without treatment with continuous positive airway pressure: an observational study. Lancet 2005; 365: 1046-1053.

4 Sahlin C, Sandberg O, Gustafson Y, et al. Obstructive sleep apnea is a risk factor for death in patients with stroke: a 10-year followup. Arch Internal Med 2008; 168: 297-301.

5 Garvey JF, Taylor CT, McNicholas WT. Cardiovascular disease in obstructive sleep apnoea syndrome: the role of intermittent hypoxia and inflammation. Eur Respir J 2009; 33: 1195-1205.

6 Roche F, Gaspoz J-M, Pichot V, et al. Association between Creactive protein and unrecognised sleep-disordered breathing in the elderly. Eur Respir J 2009; 33: 797-803.

7 Ayers L, Ferry B, Craig S, et al. Circulating cell-derived microparticles in patients with minimally symptomatic obstructive sleep apnoea. Eur Respir J 2009; 33: 574-580.

8 Hayashi M, Fujimoto K, Urushibata K, et al. Hypoxia-sensitive molecules may modulate the develoment of atherosclerosis in sleep apnoea syndrome. Respirology 2006; 11: 24-31.

9 Barceló A, Barbé $\mathrm{F}$, de la Peña $\mathrm{M}$, et al. Antioxidant status in patients with sleep apnoea and impact of continuous positive airway pressure treatment. Eur Respir J 2006; 27: 756-760.

10 Lavie L, Lavie P. Molecular mechanisms of cardiovascular disease in OSAHS: the oxidative stress link. Eur Respir J 2009; 33: 14671484 .

11 Jelic S, Padelletti M, Kawut SM, et al. Inflammation, oxidative stress, and repair capacity of the vascular endothelium in obstructive sleep apnea. Circulation 2008; 117: 2270-2278.

12 Lavie L, Vishnevsky A, Lavie P. Evidence for lipid peroxidation in obstructive sleep apnea. Sleep 2004; 27: 123-128.

13 Dalle-Donne I, Rossi R, Colombo R, et al. Biomarkers of oxidative damage in human disease. Clin Chem 2006; 52: 601-623.

14 Ohike Y, Kozaki K, Iijima K, et al. Amelioration of vascular endothelial dysfunction in obstructive sleep apnea syndrome by nasal continuous positive airway pressure. Possible involvement of nitric oxide and asymmetric NG,NG-dimethylarginine. Circ J 2005; 69: 221-226.

15 El Solh AA, Saliba R, Bosinski T, et al. Allopurinol improves endothelial function in sleep apnoea: a randomised controlled study. Eur Respir J 2006; 27: 997-1002.

16 Grebe M, Eisele HJ, Weismann N, et al. Antioxidant vitamin C improves endotelial fuction in obstructive sleep apnea. Am J Respir Crit Care Med 2006; 173: 897-901.

17 Izquierdo-Vicario Y, Ramos-Platon MJ, Conesa-Peraleja D, et al. Epworth Sleepiness Scale in a sample of the Spanish population. Sleep 1997; 20: 676-677.

18 Kushida CA, Littner MR, Morgenthaler $\mathrm{T}$, et al. Practice parameters for the indications for polysomnography and related procedures: an update for 2005. Sleep 2005; 28: 499-521.

19 Littner M, Hirshkowitz M, Davila D, et al. Practice parameters for the use of auto-titrating continuous positive airway pressure devices for titrating pressures and treating adult patients with obstructive sleep apnea syndrome. An American Academy of Sleep Medicine report. Sleep 2002; 25: 143-147.

20 Ruano J, Lopez-Miranda J, Fuentes F, et al. Phenolic content of virgin olive oil improves ischemic reactive hyperemia in hypercholesterolemic patients. J Am Coll Cardiol 2005; 46: 1864-1868.

21 Nieto FJ, Herrington DM, Redline S, et al. Sleep apnea and markers of vascular endothelial function in a large community simple of older adults. Am J Respir Crit Care Med 2004; 169: 354-360.

22 Kato M, Roberts-Thomson P, Phillips BG, et al. Impairment of endothelium-dependent vasodilation of resistance vessels in patients with obstructive sleep apnea. Circulation 2000; 102: 2607-2610.

23 Cross MD, Mills NL, Al-Abri M, et al. Continuous positive airway pressure improves vascular function in obstructive sleep apnoea/ hypopnoea syndrome: a randomised controlled trial. Thorax 2008; 63: $578-583$.

24 Teramoto S, Kume H, Matsuse $\mathrm{T}$, et al. Oxygen administration improves the serum levels of nitric oxide metabolites in patients with obstructive sleep apnea syndrome. Sleep Med 2003; 4: 403-407.

25 Gozal D, Kheirandish-Gozal L. Cardiovascular morbidity in obstructive sleep apnea: oxidative stress, inflammation, and much more. Am J Respir Crit Care Med 2008; 177: 369-375.

26 El Solh AA, Akinnusi ME, Baddoura FH, et al. Endothelial cell apoptosis in obstructive sleep apnea: a link to endothelial dysfunction. Am J Respir Crit Care Med 2007; 175: 1186-1191.

27 Lévy P, Pépin J-L, Arnaud C, et al. Intermittent hypoxia and sleepdisordered breathing: current concepts and perspectives. Eur Respir J 2008; 32: 1082-1095.

28 Ip MS, Tse HF, Lam B, et al. Endothelial function in obstructive sleep apnea and response to treatment. Am J Respir Crit Care Med 2004; 169: 348-353.

29 Lattimore JL, Wilcox I, Skilton M, et al. Treatment of obstructive sleep apnoea leads to improved microvascular endothelial function in the systemic circulation. Thorax 2006; 61: 491-495.

30 Alonso-Fernández A, García-Rio F, Arias MA, et al. Effects of CPAP on oxidative stress and nitrate efficiency in sleep apnoea: a randomised trial. Thorax 2009; 64: 581-586.

31 Carpagnano GE, Kharitonov SA, Resta O, et al. 8-Isoprostane, a marker of oxidative stress, is increased in exhaled breath condensate of patients with obstructive sleep apnea after night and is reduced by continuous positive airway pressure therapy. Chest 2003; 124: 1386-1392.

32 Lim PS, Chen WC, Wu MY, et al. Increased oxidative stress in hemodialysis patients with high risk for sleep apnea syndrome. Blood Purif 2009; 28: 144-149. 